\title{
Optimal Design of PMSA for SBW Application
}

\author{
Rached BEN MEHREZ \\ Research Unit on Signals and Mechatronic Systems SMS, \\ Ecole National d'Ingénieurs de Carthage, \\ 45 Rue des Entrepreneurs 2035 -Charguia2 -Tunis -Tunisie
}

\author{
Lilia EL AMRAOUI \\ Research Unit on Signals and Mechatronic Systems SMS, \\ Ecole National d'Ingénieurs de Carthage, \\ 45 Rue des Entrepreneurs 2035 -Charguia2 -Tunis -Tunisie
}

\begin{abstract}
In this paper a new topology of Permanent Magnet Synchronous Actuator (PMSA) is used for steer-by-wire application. The magnetic field patterns are determined from finite element modeling, for different rotor positions and supply currents, using FEMM software. The designed actuator geometric is, then, optimized using Genetic Algorithm in order to ameliorate its electromagnetic characteristics, and its resulting torque. Finally, a thermal analysis is achieved for the initial and the optimized actuators. The obtained results show a clear improvement of the actuator electromagnetic characteristics and heat distribution.
\end{abstract}

Keywords-Genetic Algorithms (GA); Permanent Magnet Synchronous Actuator (PMSA); finite elements analysis; Steer-ByWire application (SBW); Thermal study; Optimization

\section{INTRODUCTION}

Permanent Magnet Synchronous Actuators (PMSA) have become more attractive because they respond well to new technology requirements [1]. The renewed interest for these machines is due, in large part, to their excellent dynamic characteristics, low loss and their high specific torque, making them better suited to industrial applications requiring electrical drive control position or speed [2].

PMSA are suitable for low speed and high torque applications. Our contribution consists on the design of an actuating system for Steer-By-Wire (SBW) application; based on PMSA. The SBW drive system does not include gearbox, the electric machine being directly driven by the motion control system. The removal of the gearbox that typically represents a source of important losses and involves high maintenance costs is very attractive and permits the simplification of the drive cinematic conversion chain [3].

The electric machine in case of high torque applications should operate at low rotational speeds and thus it should have a large number of magnetic poles.

In the first section, the finite element model of PMSA is analyzed. Then, the finite element model of the actuator designed is optimized using a genetic algorithm. Finally electromagnetic performances of the actuator are analyzed and interpreted.

\section{StUdy ACTUATOR}

A Permanent magnet synchronous actuator (PMSA) has been applied to the performance improvement of electric power steering. Because PMSA have many advantages such as high efficiency and high torque per rotor volume, they are especially suitable for automotive applications, where space and energy savings are critical [4].

\section{A. Structure presentation}

The designed actuator shown in Fig.1 and Fig.2 has nine poles on the stator and ten poles on the rotor, with permanent magnets disposed to the rotor. Thus, for the same flux density in the air gap of the ferrite magnets with low costs can be used [5]. There is a rotary Permanent Magnet Synchronous Motor, whose polarization is substantially Albach type [6] containing the supply coils; Fig.1.a shows the Coils distribution.

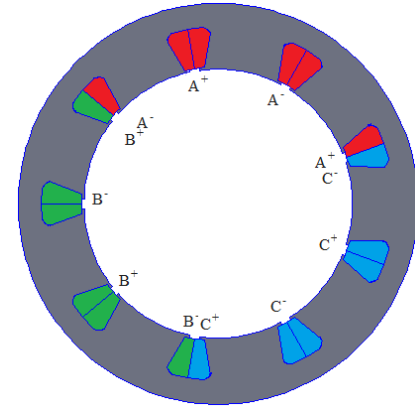

a. Two-dimensional view

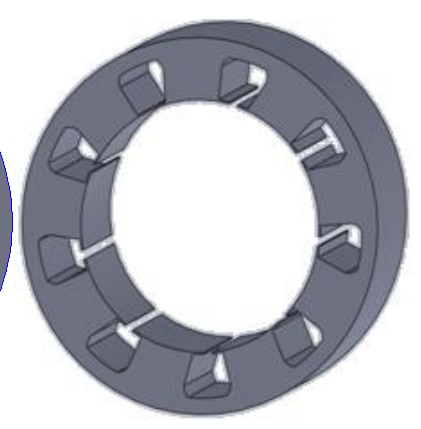

b. Perspective view
Fig. 1. Stator structure

The rotor presented by Fig.2 is composed of a ferromagnetic ring supporting 10 magnets which has radials magnetized magnet and 10 longitudinally magnetized ones, alternated.

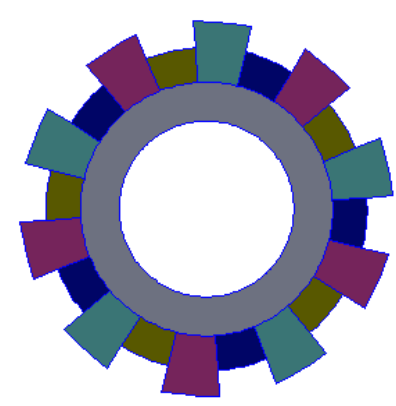

a. Two-dimensional view

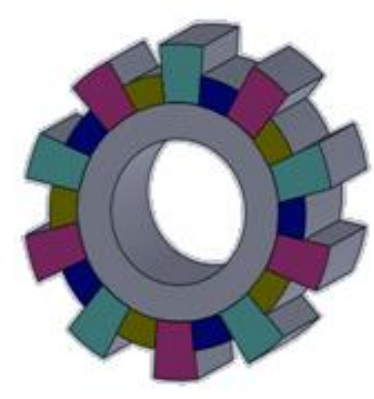

b. Perspective view
Fig. 2. Rotor structure

The designed actuator dimensions are given in Table VI.

\section{B. Magnetic characteristics}

The magnetic circuit of the rotor and the stator are made from iron-silicium $\mathrm{Fe}-\mathrm{Si}$, the stack of the stator is made of steel. Each winding consists on a coil of 63 turns, the magnetization characteristic of the Fe-Si material is shown in Fig.3. 


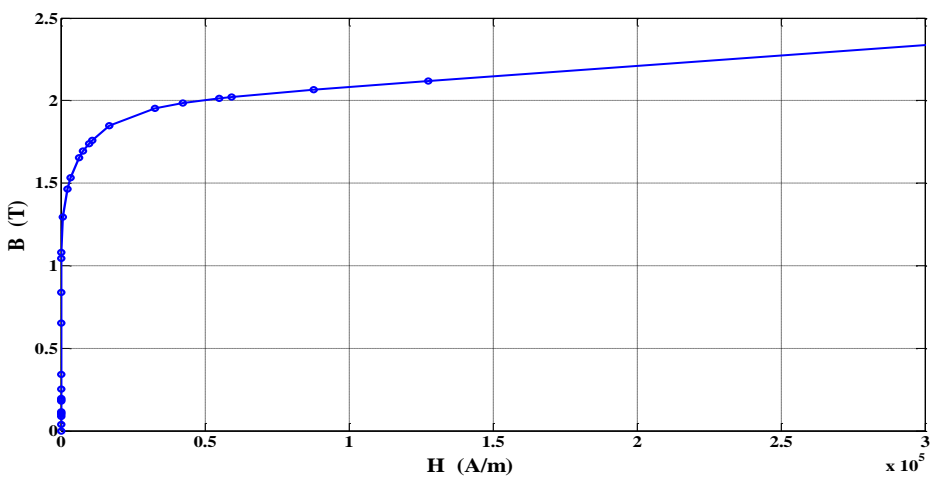

Fig. 3. Fe-Si magnetization characteristic

The ramenante induction of the magnet is equal to 1 tesla.

\section{FINITE ELEMENT MODELING OF THE STUDIED ACTUATOR}

After material characteristic assignment, meshing and solving the magnetic problem under FEMM, flux linkage, back emf, current wave form and instantaneous torque are computed.

\section{A. Flux linkage}

The induction line in the actuator is shown in Fig.4. These lines are generated by the permanent magnets for effective current density equal to $0 \mathrm{~A} / \mathrm{mm}^{2}$.

Figure 4 shows the distribution of induction lines in the actuator, for two considered positions; the first position corresponds to junction position of phases $\mathrm{A}$, the second one is shifted by $5^{\circ}$ from the first one. The induction distribution depends on the actuator moving part position.

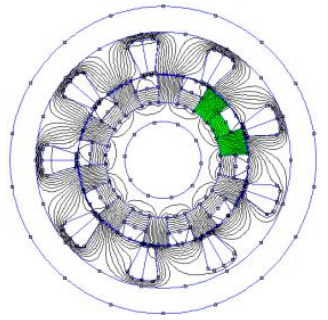

a. First position

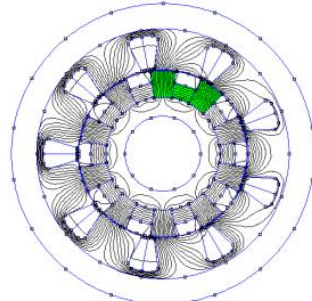

b. Second position
Fig. 4. Induction line distribution in the actuator

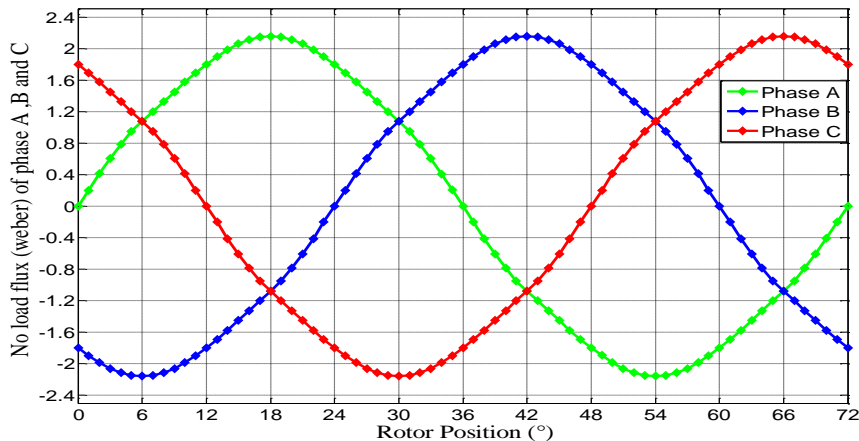

Fig. 5. No load flux of phases A, B and C according to rotor position
The no load flux developed by phases A, B and C are presented in Fig. 5. These characteristics are sinusoidal and shifted from each other by a third of the mechanical period. Thus, the corresponding flux can be approximated by the equation (1):

$$
\left\{\begin{array}{l}
\Phi_{a \text { exi }}=\sqrt{2} \Phi_{e f f} \sin \left(\frac{N_{r}}{2} \theta\right) \\
\Phi_{b e x i}=\sqrt{2} \Phi_{e f f} \sin \left(\frac{N_{r}}{2} \theta-\frac{2 \Pi}{3}\right) \\
\Phi_{c e x i}=\sqrt{2} \Phi_{e f f} \sin \left(\frac{N_{r}}{2}-\frac{4 \Pi}{3}\right)
\end{array}\right.
$$

\section{B. Electromotive Force}

Referring to the laws of Lenz, the no load back emf are given by (2):

$$
\left\{\begin{array}{l}
e_{a}=\frac{d\left(\Phi_{a e x i}\right)}{d t}=\frac{d\left(\Phi_{a \text { exi }}\right)}{d \theta} \frac{d \theta}{d t} \\
e_{b}=\frac{d\left(\Phi_{b e x i}\right)}{d t}=\frac{d\left(\Phi_{b \text { exi }}\right)}{d \theta} \frac{d \theta}{d t} \\
e_{c}=\frac{d\left(\Phi_{c e x i}\right)}{d t}=\frac{d\left(\Phi_{c \text { exi }}\right)}{d \theta} \frac{d \theta}{d t}
\end{array}\right.
$$

According to equations (1) and (2) the characteristics of back emf, depending on mechanical position, are presented in Fig.6, for a speed of $\Omega=10 \mathrm{rad} / \mathrm{s}$

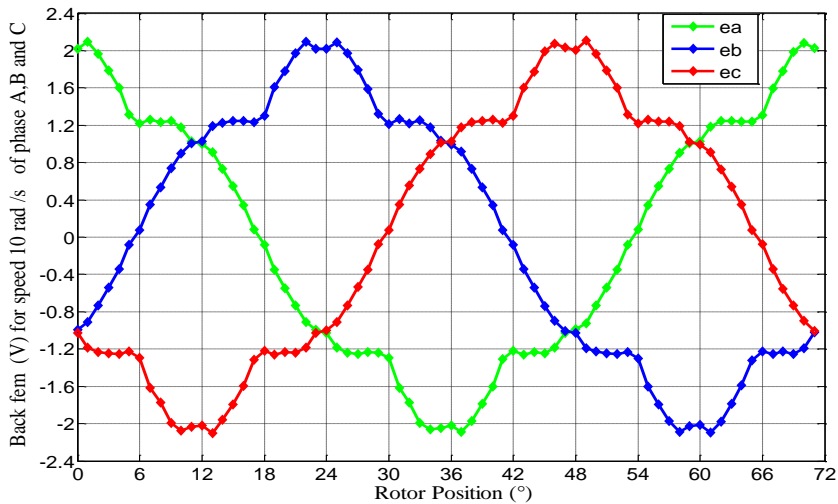

Fig. 6. Back emf for speed of $10 \mathrm{rad} / \mathrm{s}$

These characteristic are triangular wave form and shifted from each other by a third of the mechanical period.

\section{Current supply wave form}

The supply current characteristics in this case are put in phase with the back fem, which is governed by the equations (3): 


$$
\left\{\begin{array}{l}
i_{a}=\sqrt{2} \frac{J S_{s l o t} k_{b}}{N_{s p i r}} \cos \left(\frac{N_{r}}{2} \theta\right) \\
i_{b}=\sqrt{2} \frac{J S_{\text {slot }} k_{b}}{N_{\text {spir }}} \cos \left(\frac{N_{r}}{2} \theta-\frac{2 \Pi}{3}\right) \\
i_{c}=\sqrt{2} \frac{J S_{\text {slot }} k_{b}}{N_{\text {spir }}} \cos \left(\frac{N_{r}}{2} \theta-\frac{4 \Pi}{3}\right)
\end{array}\right.
$$

The current wave forms of phases $\mathrm{A}, \mathrm{B}$ and $\mathrm{C}$ according to mechanical rotor position are shown in Fig. 7.

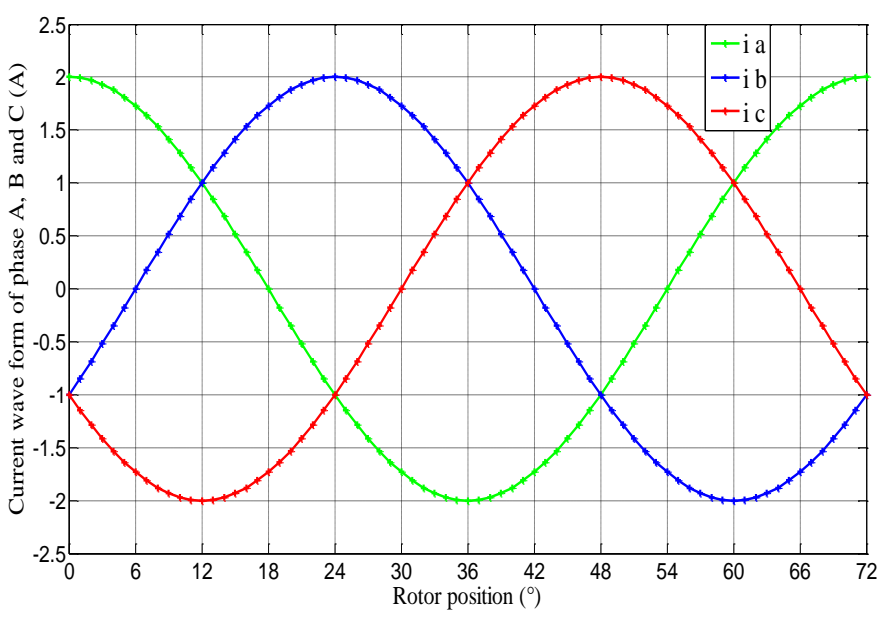

Fig. 7. Current wave form of phases $\mathrm{A}, \mathrm{B}$ and $\mathrm{C}$ according to rotor position

\section{Instantaneous torque}

For different supply current densities varying from 0 to $62 \mathrm{~A} / \mathrm{mm}^{2}$ the electromagnetic torque is computed over one mechanical period and for constant current densities, according the coenergy $W^{\prime}$ from the expression (4)

$$
C=\left.\frac{\partial W^{\prime}}{\partial \theta}\right|_{i=c s t}
$$

For determining the torque at a given position, it is necessary to carryout simulations for two near mechanical positions, while the current is kept constant. The mechanical angular variation $\Delta \theta$ between the two simulation positions gives an approximate calculation of torque performing a derivative of coenergy from (5):

$$
C=\left.\frac{W^{\prime}(\theta+\Delta \theta)-W^{\prime}(\theta)}{\Delta \theta}\right|_{i=c s t}
$$

The obtained response surface of torque, according to rotor position and current densities, is shown on Fig. 8.

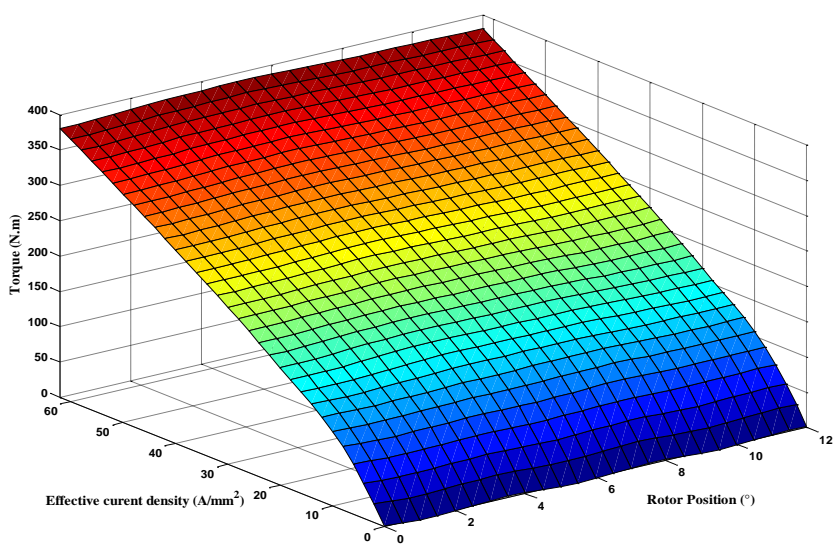

Fig. 8. Response surface of torque

The response surface of torque shows that the electromagnetic torque produced by PMSA, for a given current, is constant over the mechanical period.

\section{OPTIMIZATION OF THE DESIGNED PERMANENT MAGNET SYNCHRONOUS ACTUATOR}

The structure of the designed actuator is, in this section, optimized in order to improve the actuator electromagnetic performances, by use of the finite elements model as virtual prototype and genetic algorithm as optimization software.

The objective function is the maximization of electromagnetic torque.

\section{A. Optimization problem}

Genetic Algorithms (GA) are adaptive heuristic search algorithms based on the evolutionary ideas of natural selection and genetics. As such, these represent an intelligent exploitation of a random search used to solve optimization problems [7].

The optimization problem is described by $(\mathrm{P})$ from the expression (6):

$$
P:\left\{\begin{array}{l}
\text { Objective function: } \operatorname{Max}(C) \\
\text { parametres: } \\
25 \mathrm{~mm} \leq R_{\text {shaft }} \leq 40 \mathrm{~mm} \\
102.677 \mathrm{~mm}^{2} \leq S_{\text {slot }} \leq 551.931 \mathrm{~mm}^{2} \\
\text { under constraints } \\
R_{\text {exts }}=100 \mathrm{~mm} \\
e=0.2 \mathrm{~mm} \\
L_{a}=100 \mathrm{~mm} \\
J \quad=40 \mathrm{~A} / \mathrm{mm}^{2}
\end{array}\right.
$$


The parameters of G.A. are given by table I.

TABLE I. G.A. PARAMETERS

\begin{tabular}{|l|l|}
\hline \multicolumn{1}{|c|}{ Parameters } & \multicolumn{1}{c|}{ Valuel types } \\
\hline Generation number & 29 \\
\hline Population number & 10 \\
\hline Crossover probability & 0.8 \\
\hline Mutation probability & 0.2 \\
\hline Crossing type & Scattered \\
\hline Selection type & Stochastic uniform \\
\hline Mutation type & Uniform \\
\hline
\end{tabular}

\section{B. Results of the G.A. optimization}

The following table shows the parameters of the initial and the optimized structure of the studied actuator.

TABLE II. PARAMETERS OF INITIAL AND OPTIMIZED STRUCTURES

\begin{tabular}{|l|c|c|}
\hline \multicolumn{1}{|c|}{ Parameter } & Initial structure & Optimized structure \\
\hline $\mathrm{S}_{\text {slot }}$ & $466.688 \mathrm{~mm}^{2}$ & $332.054 \mathrm{~mm}^{2}$ \\
\hline $\mathrm{R}_{\text {shaft }}$ & $30 \mathrm{~mm}$ & $31.15 \mathrm{~mm}$ \\
\hline $\mathrm{C}$ & $273.57 \mathrm{~N} . \mathrm{m}$ & $327.15 \mathrm{~N} . \mathrm{m}$ \\
\hline
\end{tabular}

Figure 9 shows the resulting characteristics of torque developed by the initial and the optimized structures over one mechanical period.

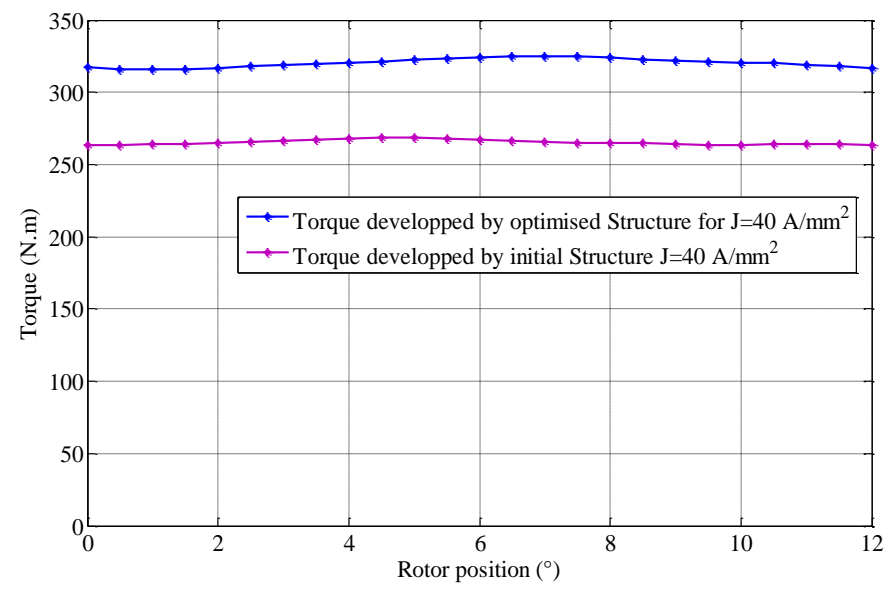

Fig. 9. Torque developed by initial and optimized PMSA structures

Referring to (3) and for different supply current densities varying from 0 to $62 \mathrm{~A} / \mathrm{mm} 2$ the electromagnetic torque of the optimized PMSA structure is computed over one mechanical period, Fig. 10.

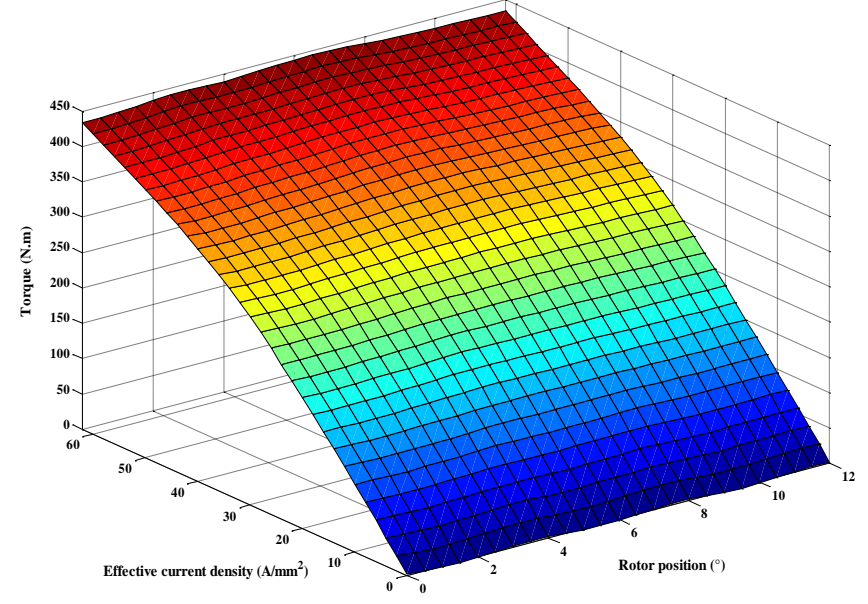

Fig. 10. Torque response surface of the optimized Actuator

\section{THERMAL STUDY OF INITIAL AND OPTIMIZED ACTUATORS}

The temperature rise is caused by the operation of rotating machines is an unavoidable natural phenomenon. Computer Aided Design (CAD) systems are used to describe geometrical models, to manipulate data and to display the results. Therefore, CAD systems with thermal analysis and computational modules become very powerful tools to investigate the thermal distribution within the electronics package, $[8,9]$.

An analysis of the temperature distribution, Fig. 11, is required to ensure that there is no concentration of heat that could cause damage during operation or demagnetization of permanent magnet.
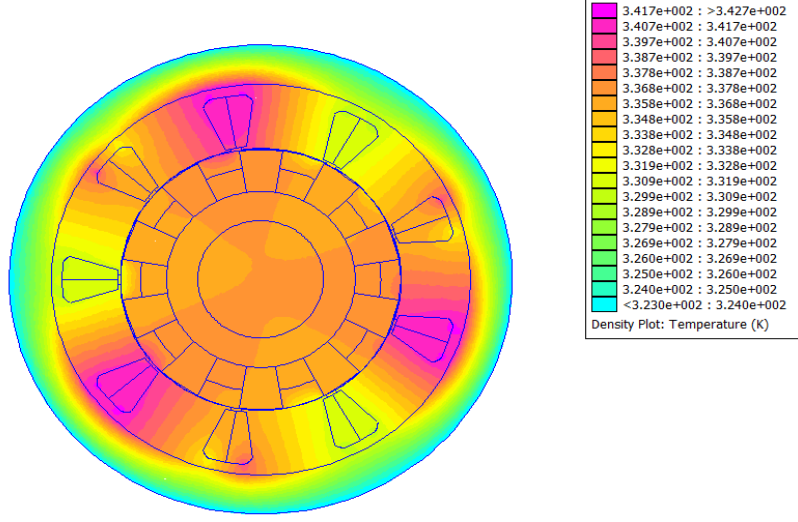

(a) 

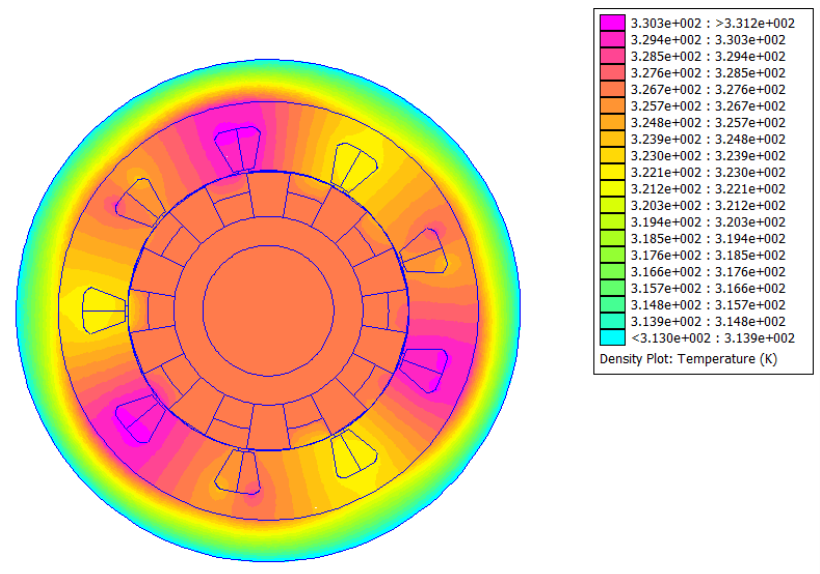

(b)

Fig. 11. Temperature distribution into actuator: Optimized structure

(a) Initial structure, (b)

The Thermal properties of materials are given in table III.

TABLE III. THERMAL PROPERTIES OF THE ACTUOR MATERIALS

\begin{tabular}{|l|l|c|c|}
\hline \multicolumn{1}{|c|}{ Segment } & \multicolumn{1}{c|}{ Material } & $\boldsymbol{\alpha}$ & $\boldsymbol{\beta}$ \\
\hline Permanent magnet & NdFeb & 3.11 & 9 \\
\hline Stator and shaft & Silicon Steel & 3.77 & $20 \mathrm{e}^{-30}$ \\
\hline Stator Slot & Copper & 3.40 & 360 \\
\hline Air gap & Air & 0.0012 & 0.025 \\
\hline
\end{tabular}

With: $\alpha$ : Specific heat capacity $\left(\mathrm{MJ} / \mathrm{m}^{3} \mathrm{~K}\right)$ and $\boldsymbol{\beta}$ : Thermal Conductivity $(\mathrm{W} / \mathrm{mK})$

Figure 12 shows the temperature cartography into initial and optimized structure. The temperature reached into the initial structure (from 323 to $341^{\circ} \mathrm{K}$ ) is higher than that obtained for the optimized structure (from 313 to $330^{\circ} \mathrm{K}$ ).

\section{RESULTS' COMPARISON}

The following table summarizes the finite element results obtained from the initial and the optimized structures.

TABLE IV. PARAMETERS AND ElECTROMAGNETIC CHARACTERISTICS OF THE INITIAL AND OPTIMIZED STRUCTURES

\begin{tabular}{|c|c|c|}
\hline & $\begin{array}{c}\text { Initial } \\
\text { structure }\end{array}$ & $\begin{array}{c}\text { Optimised } \\
\text { structure }\end{array}$ \\
\hline Nombre of phase & 3 & 3 \\
\hline Outer radius of the rotor $(\mathrm{mm})$ & 68.3 & 68.3 \\
\hline Inner radius of the rotor $(\mathrm{mm})$ & $\mathbf{3 0}$ & $\mathbf{3 1 , 1 5}$ \\
\hline Outer radius of the stator( $\left.\mathrm{R}_{\text {exts }}\right)$ & 100 & 100 \\
\hline Inner radius of the stator $(\mathrm{mm})$ & 66.3 & 66.3 \\
\hline Winding coefficient $\left(\mathrm{K}_{\mathrm{b}}\right)$ & 0.8 & 0.8 \\
\hline Phase turn number $\left(\mathrm{N}_{\text {spir }}\right)$ & $\mathbf{6 3} * \mathbf{3}$ & $\mathbf{4 4} * \mathbf{3}$ \\
\hline Air gap $(\mathrm{e})(\mathrm{mm})$ & 0.2 & 0.2 \\
\hline Number of stator teeth $(\mathrm{Ns})$ & 9 & 9 \\
\hline Number of rotor teeth $(\mathrm{Nr})$ & 10 & 10 \\
\hline Rotor iron volume $\left(\mathrm{cm}^{3}\right)$ & $\mathbf{3 5 3 . 3 7 0}$ & $\mathbf{3 3 1 . 1 5 6}$ \\
\hline Active length $\left(\mathrm{L}_{\mathrm{a}}\right)$ & 100 & 100 \\
\hline Cross section of slot $\left(\mathrm{mm}^{2}\right)$ & $\mathbf{4 6 6 . 6 8 8}$ & $\mathbf{3 3 2 . 0 5 4}$ \\
\hline Maximum torque value produced $(\mathrm{N} . \mathrm{m})$ & $\mathbf{3 7 7}$ & $\mathbf{4 3 6}$ \\
\hline Torque gains & $\mathbf{1 5 . 6 4 \%}$ \\
\hline Heat gains & $\mathbf{3} \%$ \\
\hline Rotor iron gains & $\mathbf{6 . 7 1} \%$ \\
\hline
\end{tabular}

Figure 12 shows the cartographies of the magnetic induction field corresponding to the initial and optimized actuator.
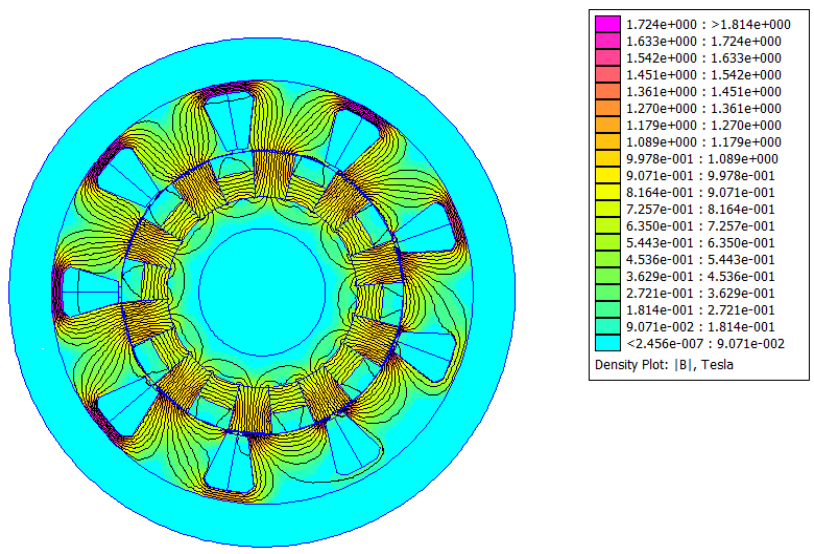

(a)
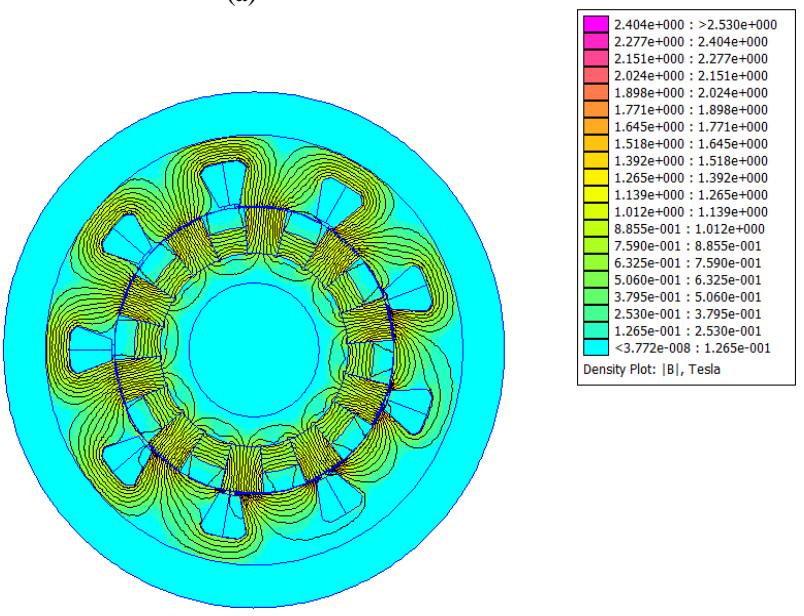

(b)

Fig. 12. Magnetic induction field: (a) Initial actuator, (b) Optimized actuator

According to the results shown on Fig. 12, it can be seen that both stator and rotor poles are much more saturated in the initial structure, than, in the optimal one.

The results' comparisons, table IV, show a torque gain of $15.64 \%$ in the optimized structure, as well as in the phase turn number, which decreases from 63 to 44. Furthermore, the rotor iron volume gain is of $6.71 \%$ and the heat level gain is of $3 \%$.

\section{CONCLUSION}

A new structure of permanent magnet actuator is designed for a steer-by-wire application. It is modeled and characterized under the finite element software FEMM environment. In the first part, the actuator initial structure is analyzed. In the second part, this structure is optimized using genetic algorithm. Finally a thermal analysis of initial and optimized structures is achieved.

The obtained results show clear improvement of torque, phase turn number, rotor iron volume and heat level in the optimized structure according to the initial one.

In future works the overall dynamic behavior of SBW direction actuated by the studied PMSA will be optimized. 
APPENDIX

\begin{tabular}{|l|l|}
\hline$C$ & Torque (N.m). \\
\hline$J$ & Effective current density $\left(\mathrm{A} / \mathrm{mm}^{2}\right)$. \\
\hline$S_{\text {slot }}$ & Slot section $\left(\mathrm{mm}^{2}\right)$. \\
\hline$N_{\text {spir }}$ & Number of turns per phase. \\
\hline$N_{s}$ & Number of stator tooth. \\
\hline$N_{r}$ & Number of rotor tooth. \\
\hline$K_{b}$ & Coefficient of winding. \\
\hline$\theta$ & Mechanical position $(\mathrm{deg})$. \\
\hline$i_{a, b, c}$ & Phase current a, b, c $(\mathrm{A})$. \\
\hline$\phi_{m i}$ & No load flux of phase $\mathrm{i}$. \\
\hline$\phi_{i j}$ & Linkage flux of phases $\mathrm{i}$ and $\mathrm{j}$ \\
\hline$e_{i}$ & Back force of phase $i$. \\
\hline$\phi_{e f f}$ & Rms value of flux. \\
\hline$\phi_{i e x i}$ & Excitation flux of phase $i$. \\
\hline$R_{\text {shaft }}$ & Radius of shaft . \\
\hline$e$ & Air-gap. \\
\hline$L_{a}$ & Active length. \\
\hline$W$ & Coenergy. \\
\hline
\end{tabular}

\section{REFERENCES}

[1] Ait-Oufroukh, N. Messaoudene, K. .Mammar S., "Dynamic model of steer-by-wire system for driver handwheel feedback", 10th IEEE International Conference on Networking, Sensing and Control (ICNSC),vol., no., pp.780,785, 10-12 April 2013.
[2] B. Singh B.P singh, S. Dwived, " A state of Art on Different Configuration of Permanent Magnet Brushless Machines "IE(I) JournalEL,pp.63-73,Vol87,June 2006.

[3] T. Tudorache, M. Popescu, "Optimal Design Solutions for Permanent Magnet Synchronous Machines," Advances in Electrical and Computer Engineering, vol. 11, no. 4, pp. 77-82, 2011.

[4] Hu Zhang, Jianwei Zhang, Konghui Guo, "An adaptive predictive current controller for Electric power steering system with Permanent Magnet Synchronous Motor," Transportation Electrification AsiaPacific (ITEC Asia-Pacific), IEEE Conference and Expo, vol., no,pp.1,6,Sept.2014.

[5] Cao, W., B. C. Mecrow, G. J. Atkinson, J. W. Bennett, and D. J. Atkinson, "Overview of electric motor technologies used for more electric aircraft (MEA)," IEEE Transactions on Industrial Electronics, Vol. 59, No. 9, p. 3523-3531, 2012.

[6] S.M. Jang, S.S. Jeong, D.W. Ryu, S.K. Choi, " Design and analysis of a high speed slotless PM machine with Halbach array ", IEEE Transactions on Magnetics, vol. 37, no. 4, pp. 2827-2830, July 2001

[7] S. Singh, S Agrawal and D.V. Avasthi, "Optimization of design parameters of glazed hybrid photovoltaic thermal module using genetic algorithm," Computational Intelligence on Power, Energy and Controls with their impact on Humanity (CIPECH) vol. no.20, pp.405,410, 28-29 Nov. 2014.

[8] A. Shah, B. G. Sammakia, H. Srihari, and K. Ramakrishna, "A numerical study of the thermal performance of an impingement heat sink-fin shape optimization," IEEE Trans. Components and Packaging Technologies, vol. 27, Issue 4, pp. 710 - 717, Dec. 2004.

[9] J. R. Culham and Y. S. Muzychka, "Optimization of plate fin heat sinks using entropy generation minimization", IEEE Trans. Components and Packaging Technologies, vol. 24, Issue 2, pp. 159 - 165, June 2001. 